Article

\title{
Application of Multi-Parameter Fuzzy Optimization to Enhance Performance of a Regulated Two-Stage Turbocharged Diesel Engine Operating at High Altitude
}

\author{
Meng Xia ${ }^{1, *}$ and Fujun Zhang ${ }^{2}$ \\ 1 School of Transportation Engineering, Beijing University of Aeronautics and Astronautics, \\ Beijing 100191, China \\ 2 School of Mechanical Engineering, Beijing Institute of Technology, Beijing 100081, China; zfj123@bit.edu.cn \\ * Correspondence: by20200423@buaa.edu.cn; Tel.: +86-130-1129-0904
}

Received: 23 June 2020; Accepted: 12 August 2020; Published: 19 August 2020

\begin{abstract}
Air intake and fuel supply conditions are the major factors that affect diesel engine performance at plateau. In a regulated two-stage turbocharged diesel engine, these parameters are reflected as the adjustment of fuel injection mass $\left(m_{f u e l}\right)$, fuel injection advance angle, and bypass valve opening of a high-pressure stage (HP) turbine. Due to the strongly nonlinear nature and complexity of the diesel engine, it is difficult to find the proper parameter combinations. That is why a model-based optimization method is adopted in this paper. The simulation model of a six-cylinder two-stage turbocharged diesel engine is built on the GT-SUITE platform. According to the analysis of diesel engine operation characteristics at high altitude, a fuzzy optimization algorithm is proposed based on a fuzzy logic controller and is realized in a MATLAB/simulink (MATLAB 2014, Mathworks, Natick, MA, USA) environment. Joint optimization of air intake and fuel supply parameters is then performed on the GT-MATLAB co-simulation platform. Results show that engine torque at full load is significantly increased. At the full load point of $2100 \mathrm{r} / \mathrm{min}$, engine power is increased from 256.5 to $319.6 \mathrm{~kW}$, and brake specific fuel consumption (BSFC) is reduced from 243.1 to $222.3 \mathrm{~g} /(\mathrm{kW} \cdot \mathrm{h}$ ). Peak torque is increased from 1944.8 to $2173.2 \mathrm{~N} \cdot \mathrm{m}$.
\end{abstract}

Keywords: diesel engine; regulated two-stage turbocharging system; model-based optimization; fuzzy optimization; co-simulation

\section{Introduction}

Atmospheric pressure and intake air density reduce at high altitude, which affects the combustion process and the performance of a diesel engine, and engine power, fuel economy, reliability, and emissions get worse [1-4]. Previous researchers have studied the effects of different altitude conditions and proposed many approaches to enhance engine performance at high altitude. Among these approaches, the improvement of air intake systems and fuel supply parameters have received great attention as hot topics in research relating to diesel engine adaptability to a high altitude environment.

The regulated two-stage turbocharging system has been used increasingly to enhance diesel engine performance at plateau in recent years [5-8]. The system can support a high compression ratio by using two-stage turbochargers. A bypass valve is implemented around the high-pressure stage (HP) turbine, which can help to regulate energy distribution between two turbochargers and adjust the compression ratio according to different working conditions. 
Some other researchers have been searching for how to improve engine performance at high altitude by adjusting fuel supplement parameters, including $m_{f u e l}$ and fuel injection advance angle. Zhu et al. [9] compared the simulation results of different schemes to adjust injection timing and fuel injection, and raised engine-rated power at the altitude of $4500 \mathrm{~m}$ to $75 \%$ of sea level. Zhou et al. [10] adjusted the injection timing and fuel injection of a common rail diesel engine at full load conditions ranging from 0 to $5000 \mathrm{~m}$, and found that this can help to improve engine combustion in the burner. Shang et al. [11] found that increasing the injection advance angle can increase combustion efficiency and engine power at plateau, but maximum combustion pressure would obviously also increase.

Very little research has been conducted to date on joint optimization of fuel and air supplement parameters to enhance diesel engine performance at plateau. Since the engine is a complex nonlinear system, it is difficult to determine the mathematical relationship among process parameters. The optimization of engine adjustable parameters should meet many constraint conditions such as exhaust temperature and maximum pressure. Model-based optimization methods have been widely used in many studies, and have gradually been applied to engine optimization of design and control parameters in recent years [12-14]. The key point is to build a reasonable simulation model and choose a proper optimization method.

Fuzzy control theory is commonly used to solve control problems with multiple inputs and a single output. It can realize system control according to human experience without knowledge of the internal structure or a mathematical model of the system, and has been widely used in engine control [14-17]. The key point is the selection of appropriate fuzzy rules between multi-objective conditions and outputs. In this paper, based on the analysis of the influence of engine adjustable parameters, multiple constraints of the engine are transformed into objective conditions, and fuzzy control theory is applied to solve the optimization problem of engine adjustable parameters. For the purpose of improving engine power and brake specific fuel consumption (BSFC) in a high altitude environment, a fuzzy logic controller-based optimization method is introduced to select the optimal combination of fuel supplement parameters and the opening of the high stage turbo bypass valve. The method is as follows. First, a simulation model of the two-stage turbocharged diesel engine is set up based on experimental data. Second, the influence of adjustable parameters is analyzed. Third, a parametric optimization method is proposed based on fuzzy logic control theory. Finally, the optimization process and results are analyzed.

\section{System Modeling and Parameter Influence Analysis}

\subsection{System Model}

The analysis is based on a six-cylinder v-type two-stage turbocharged intercooled diesel engine, which has an electronic in-line pump, and a bypass valve on the high-stage turbine. Table 1 lists the parameters of the original engine and the system schematic is presented in Figure 1. One thing to note is that the fuel injection advance angle means fuel supply advance angle in this paper.

Table 1. Engine parameters of original engine.

\begin{tabular}{cc}
\hline Parameters & Value (Unit) \\
\hline Bore & $132 \mathrm{~mm}$ \\
Stroke & $145 \mathrm{~mm}$ \\
Compression ratio & $17: 1$ \\
Maximum torque & $1980 @ 1300 \mathrm{r} / \mathrm{min}$ \\
Fuel injection advance angle & 17.5 \\
$p_{\max }$ & $165 \mathrm{bar}$ \\
\hline
\end{tabular}




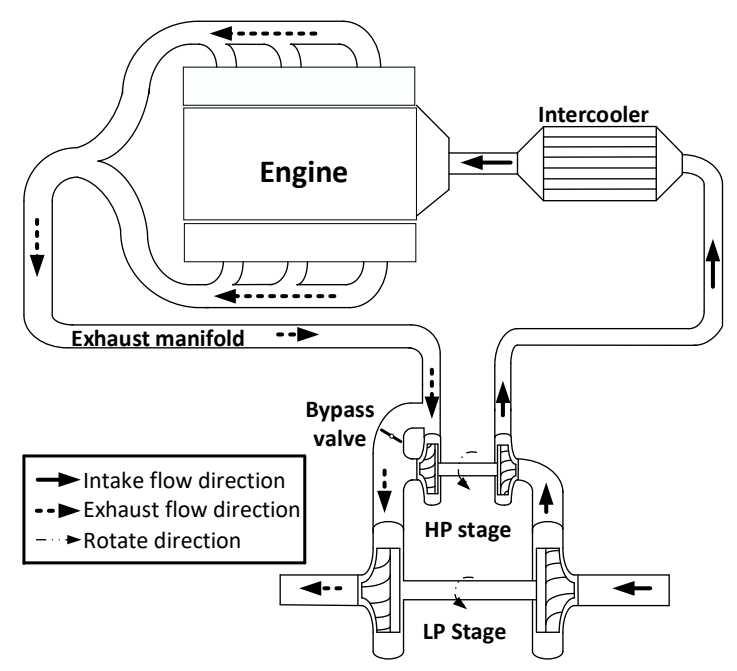

Figure 1. Schematic of regulated two-stage turbocharging system.

The combustion model is built based on a zero dimension (0-D) predictive model. The 0-D predictive model is based on a neural network $(\mathrm{NN})$ and three Wiebe functions, while a NN is used to create a mathematical model between engine characteristic parameters and nine combustion-related parameters of three Wiebe functions [18]. Air temperature after intercooling, air pressure after intercooling, $m_{f u e l}$, fuel injection advance angle, and engine speed are used as the training inputs for the NN. These parameters are strongly associated with the engine combustion process. Training data are obtained by testing in a plateau environment simulation cabin. Test conditions include $1000-2100 \mathrm{r} / \mathrm{min}$ engine speed, $10-100 \%$ load, $16.5-20.5^{\circ}$ injection timing, $0-4500 \mathrm{~m}$ altitude, $40-90{ }^{\circ} \mathrm{C}$ intercooler temperature, and $0-35^{\circ}$ turbine bypass valve opening.

Based on GT-SUITE (GT 7.3, Gamma Technologies, Westmont, IL, USA), a simulation model of the engine is built. The full-load performance of the engine model is validated by experimental data. Figure 2a shows that the simulated rate of heat release coincides well with experimental data. Figure $2 \mathrm{~b}$ shows that the related errors of output torque, intake pressure, peak pressure, and turbine inlet temperature are $3 \%, 4 \%, 2 \%$ and $7 \%$ respectively. The validation process shows that the precision of the model satisfies the requirements of optimization research.

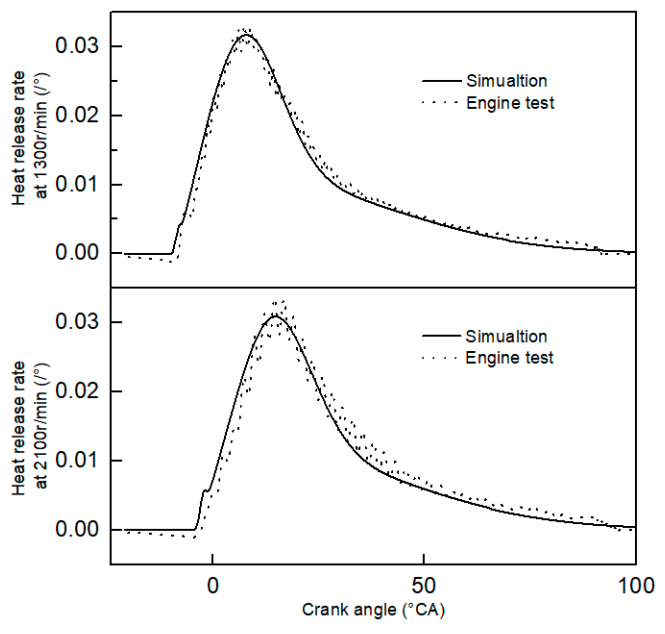

(a)

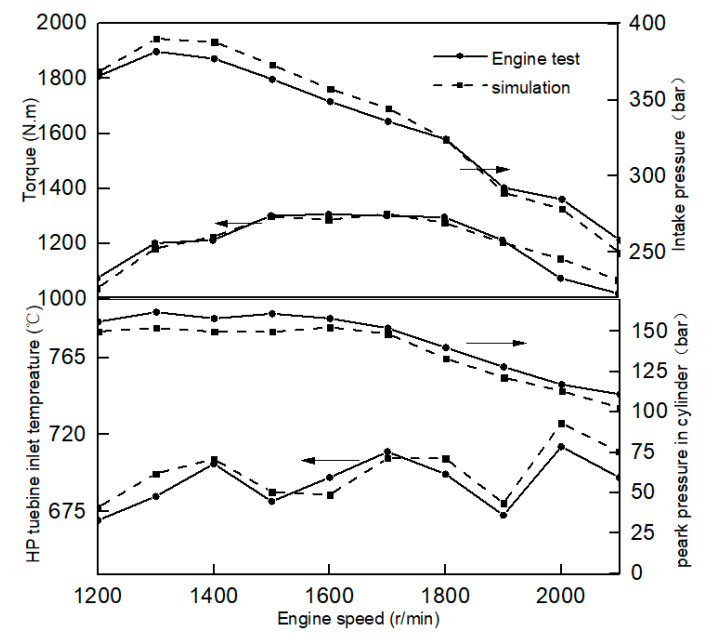

(b)

Figure 2. Calibration of simulation model. (a) Rate of heat release; (b) performance parameters. 


\subsection{Parameter Influence Analysis}

It is generally known that engine power $(P)$, exhaust temperature, and peak pressure in a cylinder $\left(p_{\max }\right)$ will increase as $m_{\text {fuel }}$ increases. The combustion process will move forward when injection is advanced, which leads to energy reduction of exhaust gas and a rise in $p_{\max }$. This has been found previously in $[9,19]$.

The simulation goes on to explore the effects of the HP turbine bypass valve opening $(\theta)$. Figure $3 a$ shows the simulation results of 1300 and $2100 \mathrm{r} / \mathrm{min} @ 120 \mathrm{mg}$ at a $4500 \mathrm{~m}$ altitude. With an increase of $\theta$, HP turbine inlet temperature $\left(T_{e x}\right)$ increases while $p_{\max }$ and the rotation speed of the HP turbocharger $\left(n_{h t c}\right)$ decrease. In addition, the torque curve of $1300 \mathrm{r} / \mathrm{min} @ 120 \mathrm{mg}$ appears to increase while that of 2100 r/min@120 mg appears to decrease.

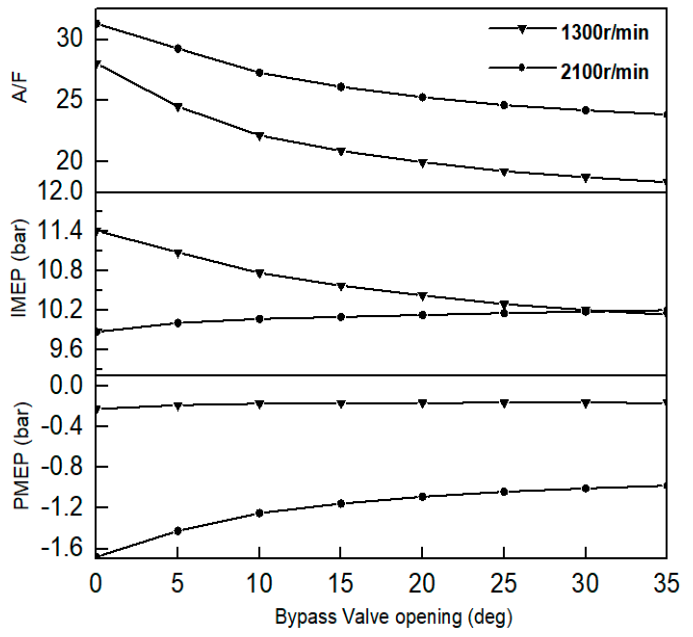

(a)

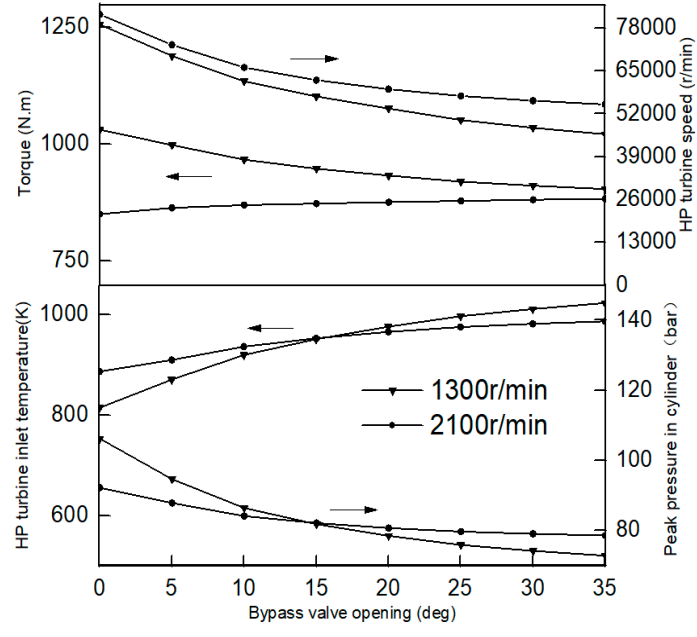

(b)

Figure 3. The influence of bypass valve opening. (a) on peak pressure in a cylinder $\left(p_{\max }\right)$, HP turbine inlet temperature $\left(T_{\mathrm{ex}}\right)$, and rotation speed of the HP turbocharger $\left(n_{\mathrm{htc}}\right) ;(\mathbf{b})$ on air fuel ratio (AFR), indicated mean effective pressure (IMEP), and pump mean effective pressure (PMEP).

As the turbine bypass valve opening increases, the air fuel ratio (AFR) and pump mean effective pressure (PMEP) both decline. The decline in AFR leads to indicated mean effective pressure (IMEP) decline. As shown in Figure 3b, at the operation point of 1300 r/min@120 mg, the decrease rate of PMEP is faster than that of IMEP, so the torque increases. At the operation point of $2100 \mathrm{r} / \mathrm{min} @ 120 \mathrm{mg}$, the decrease rate of IMEP is faster than that of PMEP, so the torque decreases.

Based on the analysis above, $m_{\text {fuel }}$, fuel injection advance angle, and $\theta$ have different impacts on engine performance. It is possible to improve engine power at plateau by adjusting these parameters. Due to interactions between these parameters, it is very hard to establish the proper combination of parameters. Constraints such as $p_{\max }, T_{e x}$, and $n_{h t c}$ should also be satisfied. That is why the fuzzy optimization method is adopted to complete this task in the next section.

\section{Design of Fuzzy Optimization Algorithm}

\subsection{Definition of Optimization Problem}

\subsubsection{Optimization Aim}

As stated above, the optimization aims of this paper are to find out the best combination of $m_{f u e l}$, fuel injection advance angle, and $\theta$, to maximize engine power, and satisfy the boundary in 
Equations (1)-(3). One thing to note is that the surge of the two-stage turbocharging system and the super speed of the low-pressure stage (LP) turbine are not considered in this paper.

$$
\begin{gathered}
p_{\max }(\vec{x}) \leq 165 \mathrm{bar}, \\
t_{T}(\vec{x}) \leq 993 \mathrm{~K}, \\
n_{T}(\vec{x}) \leq 100,000 \mathrm{r} / \mathrm{min},
\end{gathered}
$$

where $\vec{x}$ is a three-dimensional vector representing the parameters to be optimized. The sub-vectors of $\vec{x}$ are $x_{f}, x_{a}$, and $x_{0}$, which correspond to $m_{f u e l}$, fuel injection advance angle, and $\theta$ respectively; $p_{\max }(\vec{x}), t_{T}(\vec{x})$, and $n_{T}(\vec{x})$ represent $p_{\max }, T_{e x}$, and $n_{h t c}$ respectively.

\subsubsection{Boundary Transformation}

In order to show how far the constraint quantities deviate from their limiting values in a unified way, the boundary terms including $p_{\max }(\vec{x}), t_{T}(\vec{x})$, and $n_{T}(\vec{x})$ are transformed into 'violation degrees' [20] as can be seen from Equations (4)-(7).

$$
\begin{gathered}
h_{p}(\vec{x})=p_{\max }(\vec{x}) / 165-1, \\
h_{t}(\vec{x})=t_{T}(\vec{x}) / 993-1, \\
h_{n}(\vec{x})=n_{T}(\vec{x}) / 100,000-1, \\
h_{\text {turbo }}(\vec{x})=\max \left(h_{t}(\vec{x}), h_{n}(\vec{x})\right),
\end{gathered}
$$

where $h_{p}(\vec{x}), h_{t}(\vec{x})$, and $h_{n}(\vec{x})$ represent the violation degrees of $p_{\max }, T_{e x}$, and $n_{h t c}$ respectively; $h_{\text {turbo }}(\vec{x})$ represents the HP turbine related parameter. When $h_{\text {turbo }}(\vec{x})$ is greater than one, the exhaust energy is too rich and $T_{e x}$ and $n_{h t c}$ may exceed their limits.

\subsection{Fuzzy Optimization Algorithm (FLA)}

\subsubsection{Algorithm Structure}

The fuzzy optimization algorithm (FLA) is designed based on a fuzzy logic controller, and Figure 4 shows its structure. The input parameters include $p_{\max }, T_{e x}$, and $n_{h t c}$, and the output parameters include $m_{f u e l}$, fuel injection advance angle, and $\theta$.

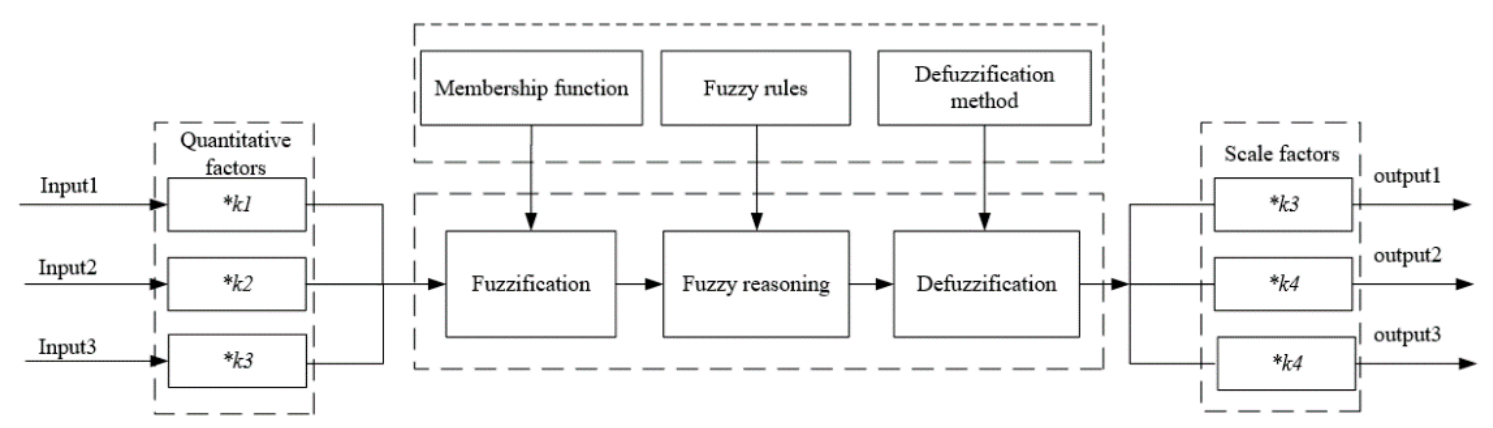

Figure 4. Structure of fuzzy optimization algorithm (FLA).

\subsubsection{Decoupling of FLA}

For a three-input three-output FLA, if the number of input lingual variables is $n$, there may be $\mathrm{n}^{3}$ fuzzy rules. It will be hard to define the fuzzy rules because they may be duplicated or omitted, so it is necessary to realize input-output decoupling. 
Figure 5a shows constraint relationships between the input and output parameters. There are two constrained boundary lines of $p_{\max }$ (or $T_{e x}$ and $n_{h t c}$ ). The solid and dashed lines denote the relationship between $m_{f u e l}$ and fuel injection advance angle when $p_{\max }$ (or $T_{e x}$ and $n_{h t c}$ ) reaches its maximum and $\theta$ is in fully open and fully closed positions respectively. When $\theta$ changes from the fully open position to the fully closed position, the $p_{\max }$ (or $T_{e x}$ and $n_{h t c}$ ) constraint line varies from the dashed line to the solid line. The shaded area is the suitable search space.

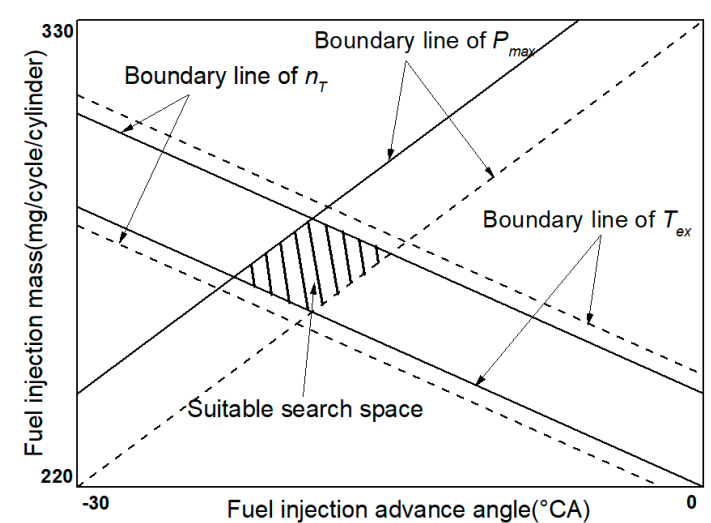

(a)

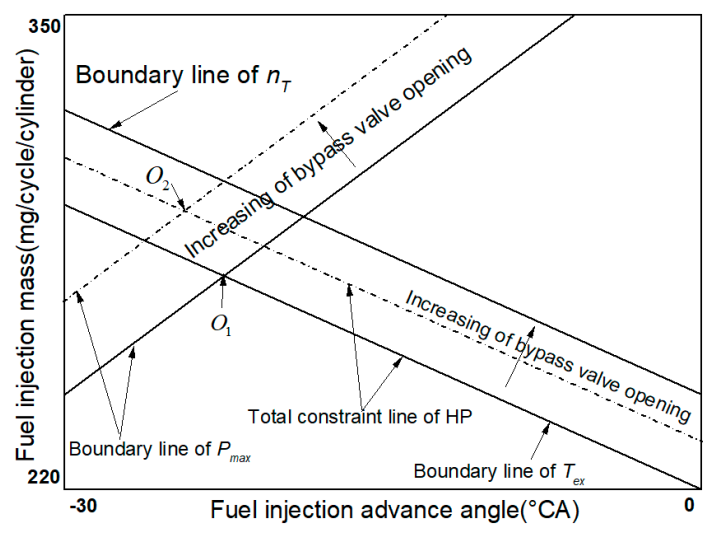

(b)

Figure 5. Decoupling process of FLA. (a) Constraint relationships; (b) Decoupling process.

For any one of the allowed values of $\theta$, the constraint lines can be simplified as shown in Figure 5b. Since the $T_{e x}$ constraint line has the same varying trend as the $n_{h t c}$ constraint line, these two constraint lines can be simplified as the total constraint line of the HP turbine, which can be seen from Figure $5 \mathrm{~b}$. The optimal point under a certain valve opening can then be determined as $O_{1}$. As $\theta$ has the opposite effect on $T_{e x}$ and $n_{h t c}$, the total constraint line of the HP turbine can be adjusted by changing $\theta$, and the $p_{\max }$ constraint line will move along with the changing value of $\theta$. Finally, the local optimum point $O_{1}$ gradually converges to the global optimum point $\mathrm{O}_{2}$ as shown in Figure $5 \mathrm{~b}$.

According to the analysis above, the three-input three-output FLA can be decoupled as two two-input two-output FLAs, namely a fuel FLA and an air FLA as shown in Figure 6, where $H_{p}, H_{t}$, $H_{n}$, and $H_{\text {turbo }}$ represent the quantized data of $h_{p}(\vec{x}), h_{t}(\vec{x}), h_{n}(\vec{x})$, and $h_{\text {turbo }}(\vec{x})$ respectively, and can be expressed in Equations (8)-(11); $\Delta i t, \Delta i m$, and $\Delta$ tang represent the variations of $m_{\text {fuel }}$, fuel injection advance angle, and $\theta$ respectively, and can be expressed in Equations (12)-(14); $\Delta I T, \Delta I M$, and $\Delta T a n g$ are the outputs of the FLA after defuzzification; $k_{f, 1}$ and $k_{f, 2}$ are quantitative factors; and $k_{f, 3}, k_{f, 4}$ and $k_{a, 3}$ are scale factors.

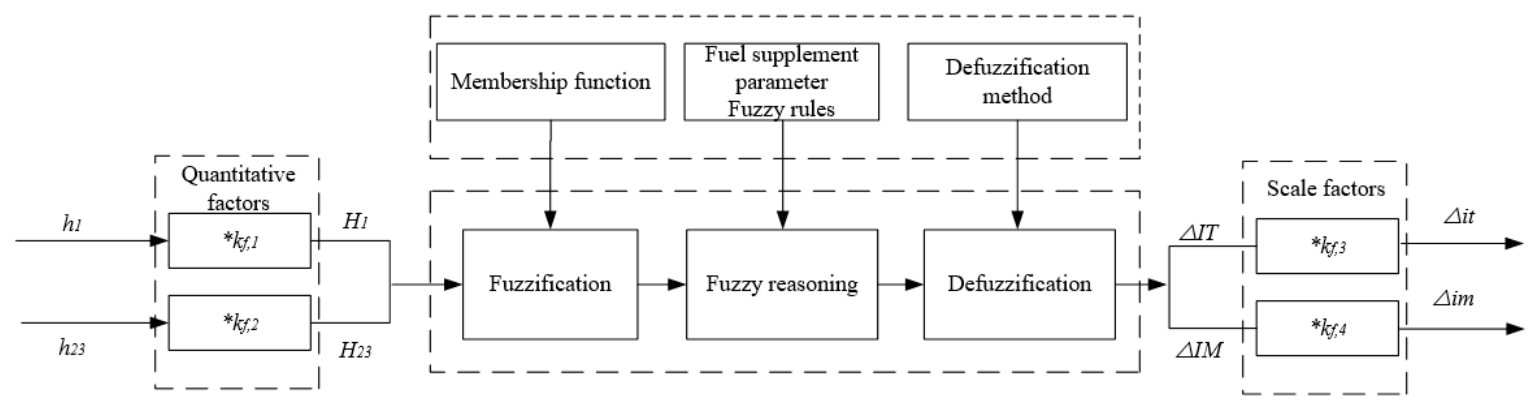

(a)

Figure 6. Cont. 


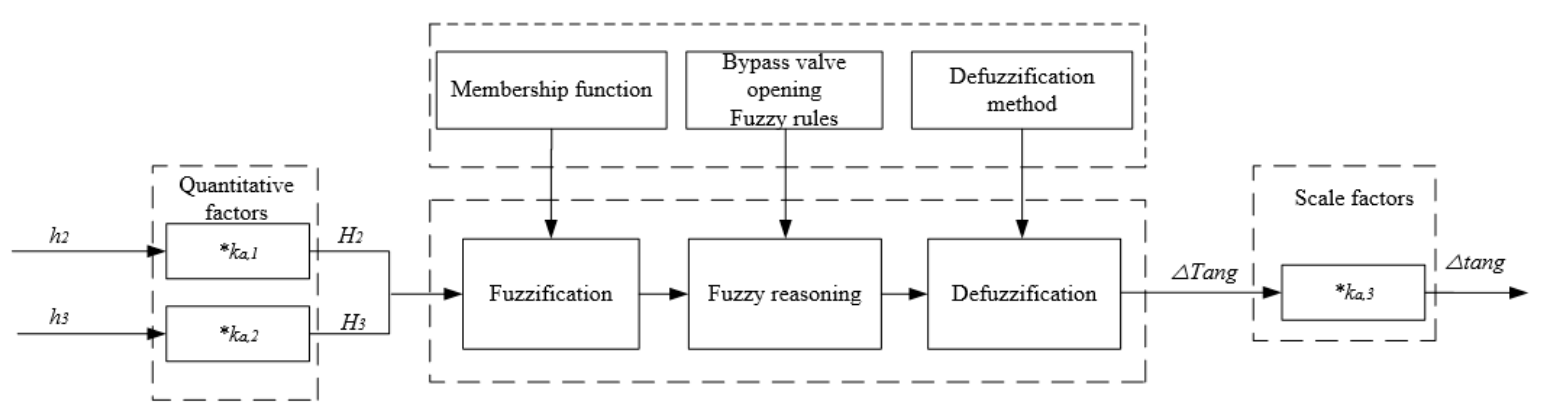

(b)

Figure 6. Two-input two-output FLA. (a) Fuel FLA; (b) air FLA.

$$
\begin{gathered}
H_{p}=\min \left(\max \left(\left(k_{f, 1} * h_{p}(\vec{x})\right),-1\right), 1\right), \\
H_{\text {turbo }}=\min \left(\max \left(\left(k_{f, 2} * h_{\text {turbo }}(\vec{x})\right),-1\right), 1\right), \\
H_{t}=\min \left(\max \left(\left(k_{a, 1} * h_{t}(\vec{x})\right),-1\right), 1\right), \\
H_{n}=\min \left(\max \left(\left(k_{a, 2} * h_{n}(\vec{x})\right),-1\right), 1\right), \\
\Delta i t=k_{f, 3} * \Delta I T, \\
\Delta i m=k_{f, 4} * \Delta I M, \\
\Delta \operatorname{tang}=k_{a, 3} * \Delta \text { Tang, }
\end{gathered}
$$

The air FLA will work if it satisfies the two conditions below, otherwise the fuel FLA will work:

(1) $\left|H_{p}\right| \leq 0.1$ and $\left|H_{\text {turbo }}\right| \leq 0.1$;

(2) $\left|H_{t}\right| \geq 0.1$ or $\left|H_{n}\right| \geq 0.1$.

\subsection{Fuzzification and Defuzzification}

Fuzzification is the process of decomposing a system input and/or output into one or more fuzzy sets [21]. Many types of curve can be used, but triangular or trapezoidal membership functions are the most common [21]. In this paper, triangular membership functions are used for fuzzification processes of the input and output. Definitions of the fuzzy set are shown in Figure 7.

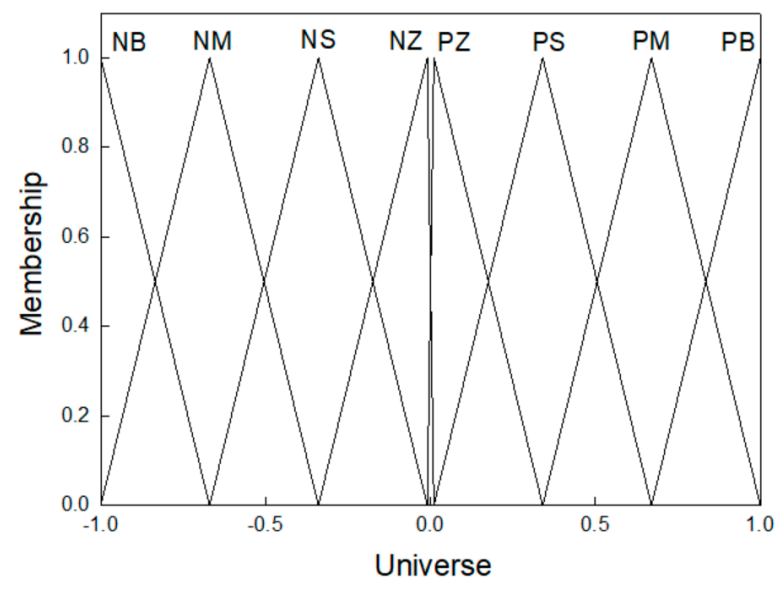

Figure 7. Fuzzy set definitions. 
Defuzzification is an inverse transformation which maps the output from the fuzzy domain back into the crisp domain [21]. The C-o-A method is often referred to as the Center-of-Gravity method because it computes the centroid of the composite area representing the output fuzzy term [21]. It is used for defuzzification in this paper.

\subsection{Converge Conditions and Optimization Realizing}

\subsubsection{Convergence Conditions}

If the calculation results meet any of the conditions for six consecutive times, fuzzy optimization is considered to be converged:

(1) $\left|H_{p}\right| \leq 0.1$ and $\left|H_{t}\right| \leq 0.1$ and $\left|H_{n}\right| \leq 0.1$;

(2) $\{\Delta$ Tang $\geq 0$ and Tang $=35\}$ or $\{\Delta$ Tang $\leq 0$ and Tang $=0\}$;

(3) $\{\Delta$ Tang $\neq 0$ or $\Delta i m \neq 0$ or $\Delta i t \neq 0\}$ and $P_{j}-P_{j-1} \leq 0$.

\subsubsection{Realization of the Optimization}

The engine model is established by GT-SUITE and co-simulated with MATLAB/Simulink. As shown in Figure 8, the joint simulation process is controlled by Simulink. Simulation data are first passed from MATLAB to GT-SUITE. Second, the GT-SUITE engine model is run and simulation results are passed to MATLAB when the GT-SUITE simulation is finished. Finally, three convergence conditions are calculated using GT-SUITE simulation data. Optimization processes continue until at least one of the three convergence conditions is met.

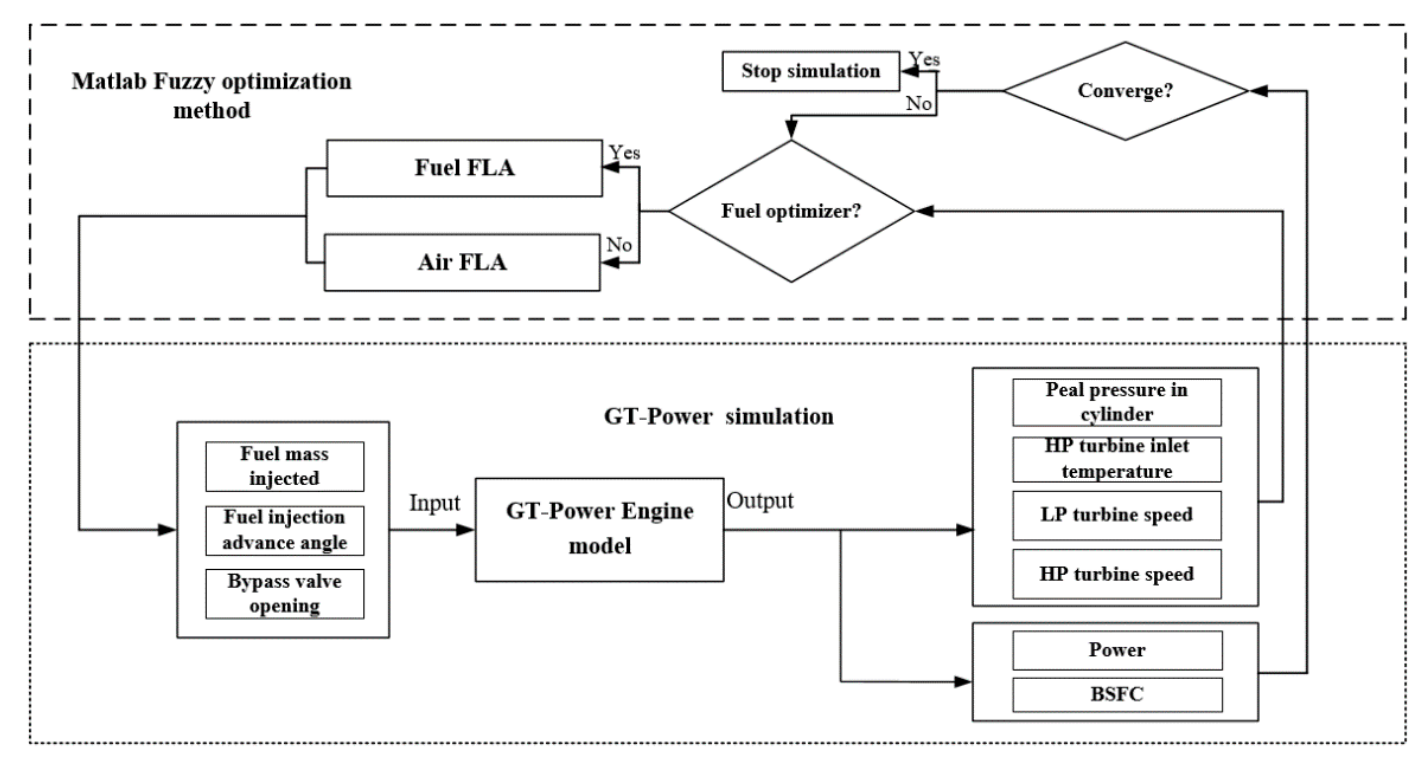

Figure 8. Co-simulation model.

\section{Discussion}

In this section, the three adjustable parameters are optimized via co-simulation based on GT-SUITE and MATLAB/simulink platforms. Simulation results at a full load point of $2100 \mathrm{r} / \mathrm{min}$ are used as an example to show the fuzzy optimization process.

\subsection{Fuzzy Optimization Process}

If the calculation results meet any of the conditions for six consecutive times, fuzzy optimization is considered to be converged. Figure 9 shows the fuzzy optimization process of the full load point at $2100 \mathrm{r} / \mathrm{min}$. During the initial phase, $T_{e x}$ and $p_{\max }$ reach their limit, but there is still space for 
adjustment of $n_{h t c}$ (see Figure $9 \mathrm{~b}$ ). Thus, the air FLA is chosen to reduce $\theta$, which leads to the rise of $p_{\max }$, and then the fuel FLA strategy starts to work to increase the fuel injection advance angle (see Figure 9a). The process is repeated until an optimal point emerges. Figure $9 \mathrm{c}$ shows engine output power and BSFC during the optimization process.

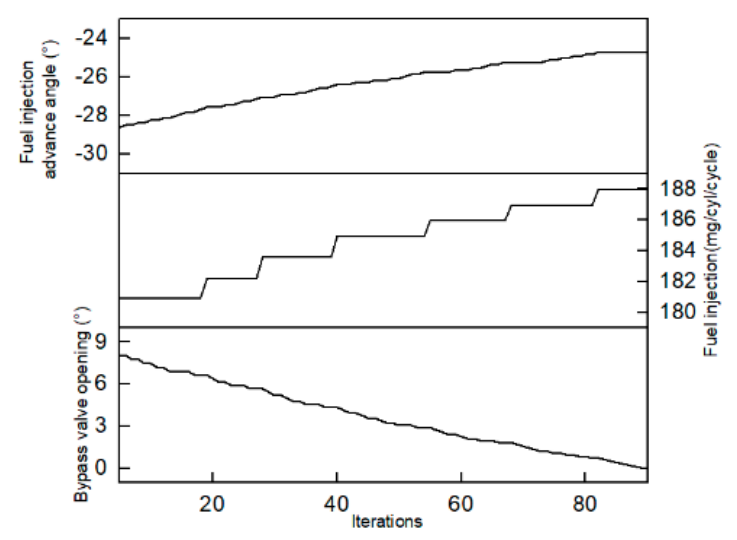

(a)

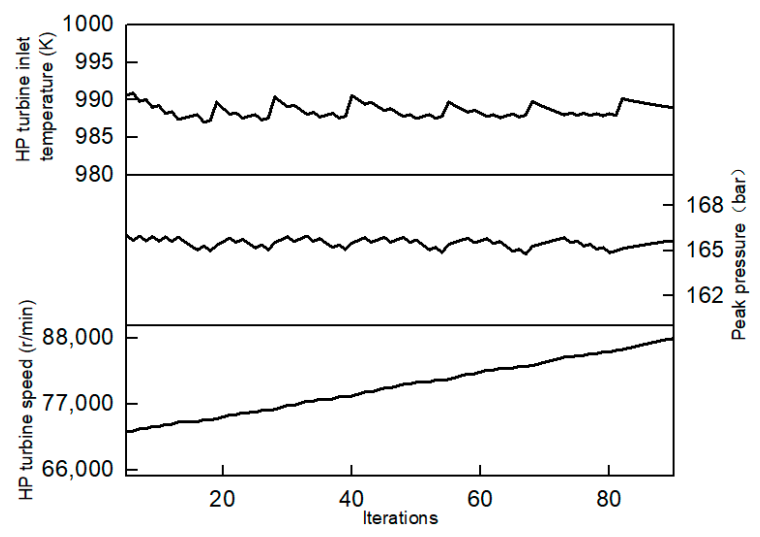

(b)

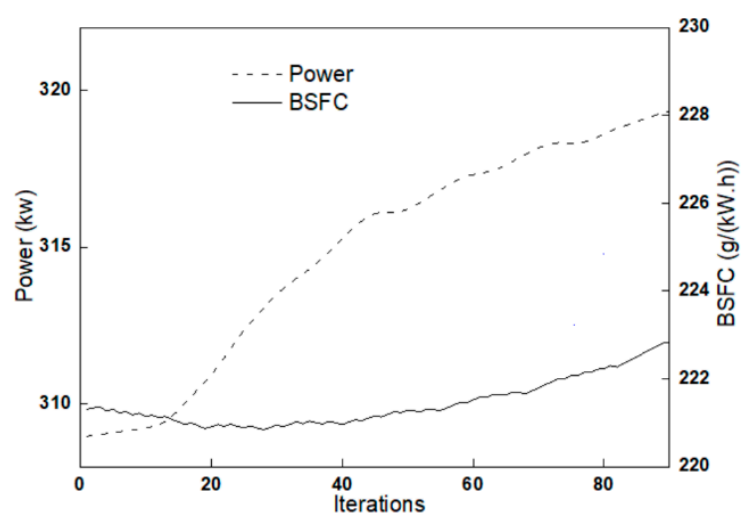

(c)

Figure 9. Optimization process at full load point of $2100 \mathrm{r} / \mathrm{min}$. (a) Optimization parameters; (b) Boundaries; (c) Engine Power and BSFC.

It can be seen that during the whole process, $T_{e x}$ and $p_{\max }$ are always kept near the limit level, and $n_{h t c}$ is gradually attracted to the limit level. The value of $m_{f u e l}$ increases and the fuel injection advance angle reduces. Finally, the simulation stops when $\theta$ matches convergence condition 2 .

\subsection{Optimization at Full Load Conditions under $4500 \mathrm{~m}$ Altitude}

Simulation was carried out on the co-simulation platform under full load conditions at $4500 \mathrm{~m}$ altitude. Table 2 shows $p_{\max }, T_{e x}$, and $n_{h t c}$ at each optimal point. $p_{\max }$ and $T_{e x}$ approximately reached the limit level, while there remains a little allowance for $n_{h t c}$, indicating that the optimized process is reasonable.

Table 2. Boundaries after optimization.

\begin{tabular}{ccccccc}
\hline Engine Speed $(\mathrm{r} / \mathrm{min})$ & 2100 & 1900 & 1700 & 1500 & 1300 & 1200 \\
\hline$p_{\max }(\mathrm{bar})$ & 165.0 & 164.4 & 164.9 & 164.8 & 164.8 & 165.3 \\
\hline$T_{e x}(\mathrm{~K})$ & 991.7 & 998.8 & 995.6 & 998.7 & 990.1 & 990.6 \\
\hline$n_{h t c}(\mathrm{r} / \mathrm{min})$ & 86,090 & 93,995 & 93,920 & 91,148 & 90,376 & 90,766 \\
\hline
\end{tabular}


Figure 10a illustrates the comparison of $m_{f u e l}$, fuel injection advance angle, and $\theta$ before and after optimization. At low and high engine speeds, $\theta$ increases to reduce PMEP and $p_{\max }$. At low to high engine speeds, the valve opening decreases to reduce $T_{e x}$. After optimization, more fuel is allowed to inject into the cylinder, and the fuel injection timing can be much earlier at mid and high engine speeds.

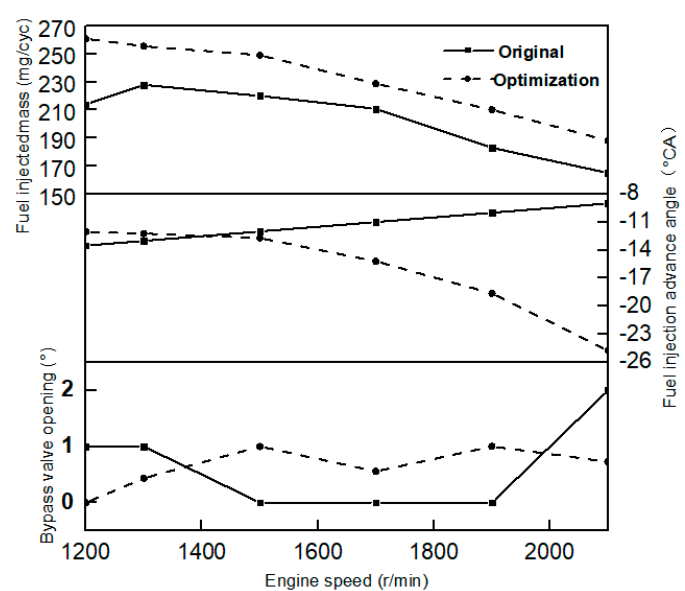

(a)

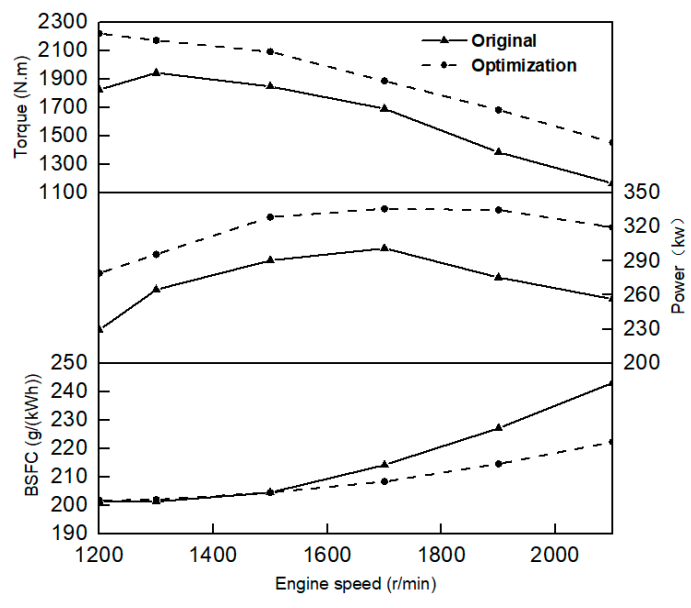

(b)

Figure 10. Comparison before and after optimization engine performance.

(a) Adjustable parameters; (b)

The optimized engine performance parameters including brake power, brake torque, and BSFC are compared with those of the original engine in Figure 10b. It is clear that these three performance parameters have been improved significantly. Maximum brake power was increased from 256.5 to $319.6 \mathrm{~kW}$. The maximum torque was also increased from 1944.8 to $2173.2 \mathrm{~N} \cdot \mathrm{m}$. When the engine speed is larger than $1500 \mathrm{r} / \mathrm{min}$, BSFC declines significantly and has a maximum decrement of $9 \%$ at a full load condition of $2100 \mathrm{r} / \mathrm{min}$.

\section{Conclusions}

In this paper, a simulation model of a two-stage turbocharged diesel engine is built based on experimental data. The influence of three adjustable parameters including $m_{f u e l}$, fuel injection advance angle, and $\theta$ is analyzed. A model-based optimization method is then used to find out the optimal combination of these three adjustable parameters. The main points of this paper can be summarized as follows.

An approach that enables joint-optimization of fuel and air supply parameters is proposed to enhance engine performance at high altitude.

The basic principles of a fuzzy logic controller are used to solve multi-objective optimization problems. When the optimal solution is located at the intersection of multiple boundaries, it may be an effective method to solve the multi constrained parameter optimization problem and to reduce the work required for parameter calibration. One thing to note is that, to simplify the definition of fuzzy rules, the number of inputs and outputs should be reduced, and in this paper the three-input three-output fuzzy logic optimizer is decoupled into two two-input two-output fuzzy logic optimizers.

Simulation results show that when the fuzzy logic optimization method is used, all performance values are improved. At the full load point of $2100 \mathrm{r} / \mathrm{min}$, engine power increases from 256.5 to $319.6 \mathrm{~kW}$, and BSFC reduces from 243.1 to $222.3 \mathrm{~g} /(\mathrm{kW} \cdot \mathrm{h})$. Maximum torque also increases from 1944.8 to $2173.2 \mathrm{~N} \cdot \mathrm{m}$. 
Author Contributions: Conceptualization, M.X. and F.Z.; Methodology, M.X. and F.Z.; Software, M.X.; Validation, M.X.; Formal Analysis, M.X. and F.Z.; Investigation, M.X.; Resources, M.X.; Data Curation, M.X.; Writing-Original Draft Preparation, M.X.; Writing-Review \& Editing, M.X.; Visualization, M.X.; Supervision, M.X.; Project Administration, College of transportation. All authors have read and agreed to the published version of the manuscript.

Funding: This research received no external funding.

Conflicts of Interest: The authors declare no conflict of interest.

\section{Nomenclature}

$n_{h t c} \quad$ Rotation speed of HP turbocharger $(\mathrm{r} / \mathrm{min})$

$p_{\text {in }} \quad$ Intake pressure (bar)

$\alpha \quad$ Fuel injection advanced angle $\left({ }^{\circ} \mathrm{CA}\right)$

AFR Air fuel ratio

$n \quad$ Engine speed

$P \quad$ Engine output power $(\mathrm{kW})$

$\theta \quad$ Bypass valve opening (deg)

$m_{f u e l} \quad$ Fuel injection mass per cylinder per cycle (mg/cycle/cylinder)

$T_{e x} \quad H P$ turbine inlet temperature (K)

$p_{\max } \quad$ Peak pressure in cylinder (bar)

0-D Zero dimension

NN Neural network

BSFC Brake specific fuel consumption

HP High-pressure stage

LP Low-pressure stage

PMEP Pump mean effective pressure

IMEP Indicated mean effective pressure

\section{References}

1. Liu, S.; Shen, L.; Bi, Y.; Lei, J. Effects of altitude and fuel oxygen content on the performance of a high pressure common rail diesel engine. Fuel 2014, 118, 243-249. [CrossRef]

2. Shen, L.Z.; Shen, Y.G.; Yan, W.S.; Xu, J.D. Combustion Process of Diesel Engines at Regions with Different Altitude (No. 950857); SAE Paper; SAE International: Warrendale, PA, USA, 1995.

3. Shen, L.Z.; Yang, Y.Z.; Lei, J.L.; Bi, Y.H.; Yan, W.S.; Yang, Y.J. Study of performance and emissions of a turbocharged inter-cooling diesel engine at different altitudes. Trans. CSICE 2006, 24, 250-255.

4. Rodgers, C. Turbocharging a high altitude UAV C. I. engine. In Proceedings of the AIAA/ASME/SAE/ASEE Joint Propulsion Conference and Exhibit, AIAA-2001-3970, Salt Lake City, UT, USA, 8-11 July 2001.

5. Xin, S.; Li, W.-X. Simulation on Plateau Performance of Diesel Engine Matched with Two-stage Sequential Turbocharging System. Acta Armamentarii 2011, 32, 397-402.

6. Li, H.; Zhang, G.; Zhang, H.; Shi, L.; Yang, M.; Deng, K. Equivalent matching model of a regulated two-stage turbocharging system for the plateau adaptability. Proc. Inst. Mech. Eng. Part D J. Automob. Eng. 2015, 230, 1654-1669. [CrossRef]

7. Changlu, Z.; Changjiang, L.; Kai, H.; Meng, X. Regulated method based on fuel economy for regulated two-stage turbocharging system of diesel at different altitudes. Trans. Chin. Soc. Agric. Mach. 2016, 47, 369-376.

8. Liu, X.H.; Wei, M.S.; Ma, C.C.; Shi, X. Simulation on one-stage and two-stage turbocharged diesel engines at different altitudes. Trans. CSICE 2010, 28, 447-452.

9. Zhu, Z.X.; Zhang, F.J.; Han, K.; Liu, Y.Y.; Luo, G.L.; Li, Y.-L. Adaption of fuel injection parameters for turbocharged diesel engines working at high altitude. Binggong Xuebao/Acta Armamentarii 2014, 35, 583-589.

10. Zhou, G.M.; Liu, R.L.; Dong, S.R.; Li, J.; Wang, W.; Zhong, Z.; Ge, F. Combustion Characteristics of Common Rail Diesel Engine under High Altitude (Low Pressure) Conditions. Neiranji Xuebao/Trans. CSICE 2012, 30, 220-226. 
11. Haikun, S.; Changlong, D.; Jianfeng, H.; Feng, F.; Ping, L.; Miandun, H.; Liang, X. Research on Compression Ratio and Fuel Injection Advance Angle Optimization of Two-stage Turbocharged Diesel engine. Binggong Xuebao/Acta Armamentarii 2017, 38, 20-26.

12. Ganapathy, T.; Murugesan, K.; Gakkhar, R.P. Performance optimization of Jatropha biodiesel engine model using Taguchi approach. Appl. Energy 2009, 86, 2476-2486. [CrossRef]

13. Zhao, J.; Xu, M. Fuel economy optimization of an Atkinson cycle engine using genetic algorithm. Appl. Energy 2013, 105, 335-348. [CrossRef]

14. Beccari, S.; Pipitone, E.; Cammalleri, M.; Genchi, G. Model-based optimization of injection strategies for SI engine gas injectors. J. Mech. Sci. Technol. 2014, 28, 3311-3323. [CrossRef]

15. Mariani, F.; Grimaldi, C.N.; Battistoni, M. Diesel engine $\mathrm{NO}_{\mathrm{x}}$ emissions control: An advanced method for the $\mathrm{O}_{2}$, evaluation in the intake flow. Appl. Energy 2014, 113, 576-588. [CrossRef]

16. Ogaji, S.O.T.; Marinai, L.; Sampath, S.; Singh, R.; Prober, S.D. Gas-turbine fault diagnostics: A fuzzy-logic approach. Appl. Energy 2005, 82, 81-89. [CrossRef]

17. Al-Hinti, I.; Samhouri, M.; Al-Ghandoor, A.; Sakhrieh, A. The effect of boost pressure on the performance characteristics of a diesel engine: A neuro-fuzzy approach. Appl. Energy 2009, 86, 113-121. [CrossRef]

18. Zhu, Z.X.; Zhang, F.J.; Wu, T.T. Zero-D predictable combustion model based on neural network and modeling. Trans. CSICE 2015, 33, 163-170.

19. Zhu, Z.; Zhang, F.; Li, C.; Wu, T.; Han, K.; Lv, J.; Li, Y.; Xiao, X. Genetic algorithm optimization applied to the fuel supply parameters of diesel engines working at plateau. Appl. Energy 2015, 157, 789-797. [CrossRef]

20. Fletcher, R. An ideal penalty function for constrained optimization 1. Nonlinear Program. 1975, 15, 319-342. [CrossRef]

21. Driankov, D.; Hellendoorn, H.; Reinfrank, M. An Introduction to Fuzzy Logic Control; DBLP: Zurich, Switzerland, 1996; pp. 1-5.

(C) 2020 by the authors. Licensee MDPI, Basel, Switzerland. This article is an open access article distributed under the terms and conditions of the Creative Commons Attribution (CC BY) license (http://creativecommons.org/licenses/by/4.0/). 